(n)

\title{
Mode of GH administration and gene expression in the female rat brain
}

\author{
Marion Walser', Linus Schiöler², Jan Oscarsson³, Maria A I Åberg4, Ruth Wickelgren5, \\ Johan Svensson', Jörgen Isgaard' 1 and N David Åberg'1 \\ 1Department of Internal Medicine, Institute of Medicine, The Sahlgrenska Academy at the University of \\ Gothenburg, Gothenburg, Sweden \\ ${ }^{2}$ Department for Public Health and Community Medicine, The Sahlgrenska Academy at the University of \\ Gothenburg, Gothenburg, Sweden \\ ${ }^{3}$ AstraZeneca Gothenburg, Mölndal, Sweden \\ ${ }^{4}$ Department of Primary Health Care, Institute of Medicine, The Sahlgrenska Academy at the University \\ of Gothenburg, Gothenburg, Sweden \\ ${ }^{5}$ Department of Clinical Chemistry and Transfusion Medicine, The Sahlgrenska Academy at the \\ University of Gothenburg, Gothenburg, Sweden
}

Correspondence should be addressed to M Walser

Email

marion.walser@medic.gu.se

\begin{abstract}
The endogenous secretion of growth hormone (GH) is sexually dimorphic in rats with females having a more even and males a more pulsatile secretion and low trough levels. The mode of $\mathrm{GH}$ administration, mimicking the sexually dimorphic secretion, has different systemic effects. In the brains of male rats, we have previously found that the mode of GH administration differently affects neuron-haemoglobin beta $(H b b)$ expression whereas effects on other transcripts were moderate. The different modes of GH administration could have different effects on brain transcripts in female rats. Hypophysectomised female rats were given $\mathrm{GH}$ either as injections twice daily or as continuous infusion and $\mathrm{GH}$-responsive transcripts were assessed by quantitative reverse transcription polymerase chain reaction in the hippocampus and parietal cortex (cortex). The different modes of GH-administration markedly increased $\mathrm{Hbb}$ and 5 '-aminolevulinate synthase 2 (Alas2) in both brain regions. As other effects were relatively moderate, a mixed model analysis (MMA) was used to investigate general effects of the treatments. In the hippocampus, MMA showed that GH-infusion suppressed glia- and neuron-related transcript expression levels, whereas $\mathrm{GH}$-injections increased expression levels. In the cortex, GH-infusion instead increased neuronrelated transcripts, whereas GH-injections had no significant effect. Interestingly, this contrasts to previous results obtained from male rat cortex where $\mathrm{GH}$-infusion generally decreased expression levels. In conclusion, the results indicate that there is a small but significant difference in response to mode of $\mathrm{GH}$ administration in the hippocampus as compared to the cortex. For both modes of $\mathrm{GH}$ administration, there was a robust effect on Hbb and Alas2.
\end{abstract}

\section{Key Words}

- growth hormone

- injections

- infusion pumps

- female

- gene transcription

\section{Introduction}

Growth hormone (GH) is a pleiotropic hormone, which apart from stimulating growth, improves mental wellbeing in several ways, such as wakefulness, energy level, concentration and memory (McGauley 1989, Nyberg \& Hallberg 2013, McEwen et al. 2015). By analogy, GH administration enhances memory parameters in 
rats (Schneider-Rivas et al. 1995, Le Greves et al. 2006) as well as expression of plasticity-related transcripts (Aberg et al. 2010).

When GH is secreted from the pituitary or administered peripherally, it stimulates the liver to release insulin-like growth factor-I (IGF-I) (Mathews et al. 1986), which mediates some of the effects of GH. In the brain, both GH and IGF1 have been shown to cross the bloodbrain barrier (Armstrong et al. 2000, Pan et al. 2005, Nishijima et al. 2010).

$\mathrm{GH}$ receptors are expressed in both glial and neuronal cells, and it is suggested that GH can stimulate both cell types directly (Lobie et al. 1993, Hallberg \& Nyberg 2012). Many of the effects of GH are related to different aspects of brain plasticity. For instance, GH treatment shows increase in cell genesis and in number of newborn neurons in the adult brain (Aberg et al. 2009, 2010). Likewise, IGF-I (D'Ercole et al. 1996, Folli et al. 1996) and IGF-I receptors are expressed in the brain by neurons, glial and endothelial cells (Yan et al. 2011). Furthermore, GH and IGF-I protect the brain against hypoxic-ischaemic injuries (HI) (Gustafson et al. 1999, Pathipati et al. 2009).

In humans and in rats, $\mathrm{GH}$ is secreted from the pituitary in a circadian rhythm that differs between the sexes. In rats, the mechanism of this sex discrepancy has been more studied than in humans. In male rats, maintaining low basal GH levels has been shown to be dependent on neonatal priming by androgens of the hypothalamus as well as by continuous adult presence of testosterone (Jansson \& Frohman 1987). In female rats, oestrogen elevates basal plasma GH levels and suppresses GH pulses (Jansson et al. 1985). Also in humans, it is believed that the sexual dimorphic GH secretion results from a response to the inhibitory effects of $17 \beta$-oestradiol and the stimulatory effect of testosterone acting on hypothalamic somatostatin release (Devesa et al. 1991). This gives rise to low trough levels and high GH peaks with 3- to 4-h intervals in male rodents, whereas more frequent peaks and almost no troughs are observed in female rodents, thereby a more even GH secretory pattern (Eden 1979, MacLeod et al. 1991). In rats, the pulsatile mode of GH treatment, which imitates the male endogenous GH secretion (Jansson et al. 1982), enhanced Igf1 mRNA levels more than infusions both in rib growth plate and in skeletal muscle (Isgaard et al. 1988). So far, the effects of different modes of GH administration have only been investigated in the hippocampus and in the parietal cortex of male hypophysectomised rats (Walser et al. 2014). Specifically, we found that the two brain regions are diversely regulated by different modes of $\mathrm{GH}$ administration to a moderate extent with the exception for the highly regulated neuronal-haemoglobin beta $(H b b)$.

However, it is not known whether the mode of GH treatment affects the female rat brain. By analogy with the different effects seen in the periphery, our hypothesis was that different modes of GH administrations, mimicking the specific secretion patterns in males and females, might give rise to responses different from those of male rat brains. Therefore, we administered GH as two daily

Table 1 Abbreviations of probes and gene names, and the names of the transcripts that are used in the present study.

\begin{tabular}{|c|c|c|c|}
\hline Gene symbol & Fullname & $\begin{array}{l}\text { Alias or abbreviation } \\
\text { in Ms }\end{array}$ & Assay number \\
\hline \multicolumn{4}{|l|}{ Transcript data } \\
\hline Ghr & Growth hormone receptor & Ghr & Rn 00567298_m1 \\
\hline $\lg 1$ & Insulin-like growth factor 1 & $\lg f 1$ & Rn 99999087_m1 \\
\hline $\lg 1 \mathrm{r}$ & Insulin-like growth factor 1 receptor & $\lg f 1 r$ & Rn 00583837_m1 \\
\hline Esr1 & Estrogen receptor 1 & Esr1 & Rn 01640372_m1 \\
\hline Hbb-b1 & Hemoglobin, beta adult major chain & $H b b$ & Rn 00583657_g1 \\
\hline Alas2 & 5'-Aminolevulinate synthase 2 & Alas2 & Rn 01637175_m1 \\
\hline Grin2a & Glutamate receptor, ionotropic, 2a (N-methyl D-aspartate receptor 2a) & Nr2a (Nmda2a) & Rn 00561341_m1 \\
\hline Dlg4 & $\begin{array}{l}\text { Discs, large (Drosophila) homolog-associated protein 4/postsynaptic } \\
\text { density-95 }\end{array}$ & Psd95 & Rn 00571479_m1 \\
\hline Gabbr1 & Gamma-aminobutyric acid $\beta$ receptor, 1 & Gabab1 & Rn 02586477_m1 \\
\hline Gria1 & Glutamate receptor, ionotropic, AMPA 1 & Gria1 & Rn 00709588_m1 \\
\hline Oprd1 & Opioid receptor, delta 1 & Dor & Rn 00561699_m1 \\
\hline Cnp & 2',3'-Cyclic nucleotide 3' phosphodiesterase & Cnp & Rn 01399463_m1 \\
\hline Gja1 & Gap junction alpha-1 protein (connexin 43) & $C \times 43$ & Rn 01433597_m1 \\
\hline Gfap & Glial fibrillary acidic protein & Gfap & Rn 00566603_m1 \\
\hline Alas1 & 5'-Aminolevulinate synthase 1 & Alas1 & Rn 00577936_m1 \\
\hline Hif1a & Hypoxia-inducible factor 1, alpha subunit & Hif1 $\alpha$ & Rn 01472831_m1 \\
\hline Gapdh & Glyceraldehyde 3-phosphate dehydrogenase & Gapdh & Rn 01462662_g1 \\
\hline
\end{tabular}


injections or as infusions by osmotic minipumps, and investigated the effects on previously known transcripts related to plasticity and transcripts related to oxygenation in the hippocampus and parietal cortex (henceforth cortex). The transcripts were divided into four categories (Walser et al. 2014): GH-, neuron-, glia-related and neuronHbb (Table 1 and Supplementary Table 1 for further details, see section on supplementary data given at the end of this article). Three transcripts, which have not been studied before, were also measured as they are functionally associated with $\mathrm{Hbb}$ and oxygenation (Walser et al. 2014). These were the rate-limiting enzymes of the haeme synthesis delta-aminolevulinate synthase 1 and 2 (Alas1, Alas2) and the hypoxia-inducible factor 1-alpha (HIF1a), which functions as a master transcriptional regulator of the adaptive response to hypoxia (Table 1, for further details see Supplementary Table 1).

\section{Materials and methods}

\section{Animals and hormonal treatment}

The experiments were performed in female $(n=21)$ Sprague-Dawley rats (Møllegaard Breeding Center Ltd, Ejby, Denmark), as previously described ((Walser et al. 2011) and Supplementary information). Normal pituitaryintact rats (henceforth intact) and hypophysectomised rats (henceforth $\mathrm{Hx}$ ) were kept to monitor effects of $\mathrm{Hx}$ per se, and to evaluate whether bovine-GH (bGH) restored specific transcript expression to relevant physiological levels.

The effects of hormonal administration were assessed in rats, which were Hx at 60 days of age ( $n=5-6$ in each group). Hormone administration was maintained for 7 days and initiated 10 days after $\mathrm{Hx}$, to sort out rats with incomplete $\mathrm{Hx}$ as determined by weight gain. All Hx rats received substitution therapy with cortisol phosphate (C; $400 \mu \mathrm{g} / \mathrm{kg} /$ day; Solucortef, Upjohn, Puurs, Belgium) and L-thyroxine $\left(\mathrm{T}_{4} ; 10 \mu \mathrm{g} / \mathrm{kg} /\right.$ day; Nycomed, Oslo, Norway), which were diluted in saline and administered subcutaneously once daily at 08:00 h (Jansson et al. 1982). These rats were randomised into a control group $(\mathrm{Hx})$ and two bovine GH (bGH)-groups. Bovine GH (recombinant), donated by American Cyanamide Co (Princeton, NJ, USA), was prepared as described before and given as a subcutaneous continuous infusion $(0.7 \mathrm{mg} / \mathrm{kg}$ per day) for 7 days using mini-osmotic pumps (Alzet 2004 model) implanted subcutaneously in the neck (henceforth $\mathrm{GHi}$ ) or as subcutaneous injections (henceforth GHx2; i.e. $0.35 \mathrm{mg} / \mathrm{kg}$, twice daily, equalling a total of $0.7 \mathrm{mg} / \mathrm{kg}$ per 24h) (Oscarsson et al. 1999). Tissues were immediately dissected and frozen in liquid nitrogen and stored at $-80^{\circ} \mathrm{C}$. All treatment procedures were approved by the Board of Animal Ethics of the University of Gothenburg. Of note is that samples from the intact, $\mathrm{Hx}$ and GHi groups have been used in previous experiments (Walser et al. 2011) but the transcripts assessed then (Hbb, Gabbr1) have here been re-analysed with quantitative reverse transcription polymerase chain reaction (Q-RT-PCR) using new primers.

\section{Quantitative reverse transcription polymerase chain reaction (Q-RT-PCR)}

To quantify the different transcripts, we used the Q-RTPCR. Total RNA was extracted from hippocampus and cortex using the Tri Reagent solution (Ambion) and quantified by spectrophotometric analysis of absorption at 260 vs $280 \mathrm{~nm}$ using a Nanodrop 1000 (Thermo Scientific). cDNA was prepared from 250 ng total RNA, (High-Capacity cDNA Reverse Transcription Kit, Applied Biosystems). Q-RT-PCR analysis was performed using an ABI Prism 7900 Sequence Detection System (Applied Biosystems). Predesigned, TaqMan Gene Expression Assays were used (Applied Biosystems) (Table 1, for further details see http://www.appliedbiosystems.com).

Detailed information and references on the transcripts are found in Table 2. For information on the calculations of the Q-RT-PCR, Supplementary information (Walser et al. 2014).

\section{Statistical analysis}

Values are presented as the mean $\pm 95 \%$ confidence interval (CI). Comparisons between any two groups were made using unpaired $t$-tests (Table 4). As the primary objective was to compare GHi and GHx2, these analyses were not corrected for multiple comparisons. Furthermore, as the transcripts were selected for previous GH-responsiveness, other secondary comparisons are shown for convenience but are not corrected for multiple comparisons. Correlations were calculated according to the Pearson correlation coefficient expressed as $r$.

A mixed model analysis (MMA) was used for all other statistical comparisons, such as to evaluate effects of $\mathrm{GHi}$ and GHx2 related to each of the categories of transcripts. For further information on the MMA, Supplementary 
Table 2 Key references for the transcripts that are predominantly expressed in glial or neuronal cells.

\begin{tabular}{|c|c|c|}
\hline Abbreviation & $\begin{array}{l}\text { Primarily in } \\
\text { cell type }\end{array}$ & Designated category in Ms \\
\hline Ghr & Neuron/glia & GH-related $(\mathrm{GH})$ \\
\hline $\operatorname{lgf1}$ & Neuron/glia & GH-related $(\mathrm{GH})$ \\
\hline $\lg 1 \mathrm{r}$ & Neuron/glia & GH-related $(\mathrm{GH})$ \\
\hline Esr1 & Neuron/glia & GH-related $(\mathrm{GH})$ \\
\hline $\mathrm{Hbb}$ & Neuron & $\begin{array}{l}\text { Neuron/Hbb-related } \\
(\mathrm{N}-\mathrm{Hbb})\end{array}$ \\
\hline Alas2 & Neuron & $\begin{array}{l}\text { Neuron/Hbb-related } \\
(\mathrm{N}-\mathrm{Hbb})\end{array}$ \\
\hline $\mathrm{Nr} 2 \mathrm{a}$ & Neuron & Neuron - related $(\mathrm{N})$ \\
\hline Psd95 & Neuron & Neuron - related $(\mathrm{N})$ \\
\hline Gabab1 & Neuron & Neuron - related $(\mathrm{N})$ \\
\hline Gria1 & Neuron & Neuron - related $(\mathrm{N})$ \\
\hline Dor & Neuron (glia) & Neuron - related $(\mathrm{N})$ \\
\hline Cnp & Glia & Glia-related (G) \\
\hline Cx43 & Glia & Glia-related (G) \\
\hline Gfap & Glia & Glia-related (G) \\
\hline Alas1 & Glia & Glia-related (G) \\
\hline Hif1a & Glia & Glia-related (G) \\
\hline
\end{tabular}

\begin{tabular}{l} 
Main function \\
\hline Brain plasticity \\
Brain plasticity \\
Brain plasticity \\
Brain plasticity \\
O2-regulatory protein \\
Rate-controlling enzyme of heme \\
biosynthesis \\
Hippocampal synaptic plasticity \\
Hippocampal synaptic plasticity \\
Inhibitory neurotransmitter/ \\
neuroprotection \\
Excitatory neurotransmitter \\
receptors \\
Neuroprotective effects \\
Formation of the myelin sheath \\
Cell communication \\
Excitatory neurotransmitter/ \\
morphogenesis \\
Rate-controlling enzyme of heme \\
biosynthesis \\
Hypoxia-induced signaling protein
\end{tabular}

\author{
Reference(s) \\ Le Greves et al. (2002) \\ Lopez-Fernandez et al. (1996) \\ De Geyter et al. (2016) \\ Pons \& Torres-Aleman (1993) \\ He et al. (2009), Walser et al. (2014)
}

Sadlon et al. (1999)

Le Greves et al. (2002, 2006)

Le Greves et al. (2006)

Xu et al. (2008)

Martin et al. (1993)

Persson et al. (2003)

Aberg et al. (2007)

Aberg et al. (2000)

Pekny et al. (1995)

Thunell (2006)

Ziello et al. (2007)

For more details on exact effects and previous effects by GH/IGF-I administration, see Supplementary Table 1.

information (Walser et al. 2014). $P<0.05$ were considered statistically significant.

\section{Results}

\section{GH exerts systemic effects}

Hx rats received bGH either as subcutaneous infusion (GHi) or injections twice daily (GHx2) for 7 days. bGH normalised weight gains in $\mathrm{Hx}$ rats to slightly above the weight gain observed in intact rats $(P<0.001)$ (Table 3), indicating that the administered GH had the expected systemic effect on body growth. Of note is that GHx2 increased weight gain significantly more (+20\%) than GHi.

Table 3 Weight gains of experimental animals treated with bGH for 7 days.

\begin{tabular}{|c|c|c|c|}
\hline & \multirow[b]{2}{*}{ Weight gain (g) } & \multicolumn{2}{|c|}{ T-test ( $P$-values) } \\
\hline & & Each vs hx & Ghi vs GHx2 \\
\hline Intact & $3.60 \pm 0.38$ & $<0.001$ & \\
\hline $\mathrm{Hx}$ & $-0.01 \pm 0.11$ & & \\
\hline $\mathrm{Hx}+\mathrm{GHi}$ & $3.76 \pm 1.78$ & $<0.001$ & \\
\hline $\mathrm{Hx}+\mathrm{GH} \mathbf{2}$ & $4.53 \pm 0.10$ & $<0.001$ & 0.022 \\
\hline
\end{tabular}

Two-tailed $T$-tests are performed relative $\mathrm{Hx}$ and between $\mathrm{GHi}$ and $\mathrm{GH} \times 2$. Values are given as means $\pm 95 \%$ confidence intervals (Cls).
$\mathrm{GH}$ administration produces a robust response in $\mathrm{Hbb}$ and Alas2 expression but has a moderate influence on other transcripts in both the hippocampus and cortex

The selection of transcripts investigated in this study is based on results from previous studies showing that they are regulated by $\mathrm{GH}$ treatment in the adult male rat brain, and divided into GH-, neuron- or glia-related transcripts (Tables 1, 2 and Supplementary Table 1).

Overall, both GHi and GHx2 induced small and in most cases non-significant changes in transcript abundance, except for the robust increases in $\mathrm{Hbb}$ and Alas2 (Table 4). In most cases, there was some agreement with previous reports but not necessarily in both brain regions or for both modes of administration. Hx per se only significantly affected a few transcripts, namely Alas2 $(P=0.001)$ in the hippocampus and $\mathrm{Hbb}(P=0.005)$, Esr1 $(P=0.023)$, Gria1 $(P=0.029)$ and Alas $(P=0.042)$ in the cortex.

When testing our primary hypothesis, whether there was different magnitude in response to $\mathrm{GHi}$ or $\mathrm{GHx} 2$, only a few specific transcripts exhibited statistically significant differences Gfap, Igf1r, Psd95 and Alas1 in the hippocampus, and $H b b, P s d 95$ and Hif1 $\alpha$ in the cortex (Table 4). It is of note that in all these cases, GHx2 showed a higher response than GHi in the hippocampus, whereas the opposite, except for $H b b$, was the case in the cortex.

Published by Bioscientifica Ltd. 
Table 4 The relative mean values for the transcripts $\pm 95 \%$ confidence intervals $(\mathrm{Cls})$.

\begin{tabular}{|c|c|c|c|c|c|c|}
\hline Cat. & Transcript & Group & Hippocampus & $\boldsymbol{N}$ & Cortex & $\boldsymbol{N}$ \\
\hline \multirow[t]{4}{*}{$\mathrm{GH}$} & Ghr & Intact & $100.0(77.6-122.4)$ & 6 & $100.0(65.2-134.8)$ & 5 \\
\hline & & $\mathrm{Hx}$ & $98.2(75.7-120.7)$ & 6 & $95.4(64.1-126.6)$ & 6 \\
\hline & & $\mathrm{GHi}$ & 95.6 (71.0-120.2) & 5 & 91.7 (57.5-126.0) & 5 \\
\hline & & $\mathrm{GH} \times 2$ & $128.8(101.3-156.4)$ & 4 & $107.1(72.9-141.4)$ & 5 \\
\hline \multirow{4}{*}{$\mathrm{GH}$} & lgf1 & Intact & $100.0(74.9-125.1)$ & 6 & $100.0(59.5-140.5)$ & 5 \\
\hline & & $\mathrm{Hx}$ & $76.3(54.3-98.3)$ & 6 & $119.7(82.8-156.6)$ & 6 \\
\hline & & $\mathrm{GHi}$ & 97.2 (73.1-121.4) & 5 & 109.1 (68.7-149.6) & 5 \\
\hline & & $\mathrm{GH} \times 2$ & $103.2(76.2-130.2)$ & 4 & $78.3(37.8-118.7)$ & 5 \\
\hline \multirow[t]{4}{*}{ GH } & $\lg f 1 r$ & Intact & $100.0(79.9-120.1)$ & 6 & $100.0(72.4-127.6)$ & 5 \\
\hline & & $\mathrm{Hx}$ & $97.1(76.9-117.2)$ & 6 & 73.7 (47.0-100.4) & 6 \\
\hline & & $\mathrm{GHi}$ & $80.1(58.0-102.2)^{\dagger}$ & 5 & $99.9(70.6-129.1)$ & 5 \\
\hline & & $\mathrm{GH} \times 2$ & $114.7(90.1-139.4)$ & 4 & $71.0(41.7-100.3)$ & 5 \\
\hline \multirow[t]{4}{*}{$\mathrm{GH}$} & Esr1 & Intact & $100.0(76.2-123.8)$ & 6 & $100.0(73.6-126.4)$ & 5 \\
\hline & & $\mathrm{Hx}$ & $109.7(83.7-135.7)$ & 6 & $57.7(32.1-83.3)^{\ddagger}$ & 6 \\
\hline & & $\mathrm{GHi}$ & $101.2(72.7-129.7)$ & 5 & 56.5 (25.9-87.1) & 4 \\
\hline & & $\mathrm{GH} \times 2$ & $115.9(84.0-147.7)$ & 4 & 69.3 (34.7-103.8) & 3 \\
\hline \multirow[t]{4}{*}{$\mathrm{N}-\mathrm{Hbb}$} & $H b b$ & Intact & $100.0(47.9-152.1)$ & 6 & $100.0(64.3-135.7)$ & 5 \\
\hline & & $\mathrm{Hx}$ & $34.3(-31.8$ to 100.4$)$ & 6 & $22.5(-10.5 \text { to } 55.6)^{\ddagger \ddagger}$ & 6 \\
\hline & & $\mathrm{GHi}$ & $147.1(74.7-219.5) *$ & 5 & $55.3(19.1-91.5)^{\dagger}$ & 5 \\
\hline & & $\mathrm{GH} \times 2$ & $131.0(50.0-211.9)$ & 4 & $111.4(75.2-147.6) * *$ & 5 \\
\hline \multirow[t]{4}{*}{$\mathrm{N}-\mathrm{Hbb}$} & Alas2 & Intact & $100.0(79.5-120.5)$ & 5 & $100.0(42.9-157.1)$ & 4 \\
\hline & & $\mathrm{Hx}$ & $47.7(-15.4 \text { to } 110.8)^{\ddagger \neq}$ & 6 & $22.9(-6.5 \text { to } 52.4)^{\ddagger}$ & 6 \\
\hline & & $\mathrm{GHi}$ & $127.1(57.9-196.2)$ & 5 & $75.1(42.8-107.3)^{\star}$ & 5 \\
\hline & & $\mathrm{GH} \times 2$ & $190.7(113.4-268.0) * *$ & 4 & $98.2(65.9-130.5) * *$ & 5 \\
\hline \multirow[t]{4}{*}{$\mathrm{N}$} & Grin2a & Intact & $100.0(78.4-121.6)$ & 6 & $100.0(68.7-131.3)$ & 5 \\
\hline & & $\mathrm{Hx}$ & $91.8(67.5-116.2)$ & 6 & 71.1 (44.5-97.7) & 6 \\
\hline & & $\mathrm{GHi}$ & 73.9 (47.3-100.6) & 5 & 100.5 (71.4-127.9) & 5 \\
\hline & & $\mathrm{GH} \times 2$ & $113.6(83.8-143.4)$ & 4 & $65.4(36.3-94.6)$ & 5 \\
\hline \multirow[t]{4}{*}{$\mathrm{N}$} & $D \lg 4$ & Intact & $100.0(79.5-120.5)$ & 6 & $100.0(55.8-144.2)$ & 5 \\
\hline & & $\mathrm{Hx}$. & $97.9(79.9-115.8)$ & 6 & $113.1(75.4-150.8)$ & 6 \\
\hline & & $\mathrm{GHi}$ & $78.0(58.4-97.7)^{\dagger}$ & 5 & $131.6(90.3-172.9)^{\dagger}$ & 5 \\
\hline & & $\mathrm{GH} \times 2$ & 111.9 (89.9-133.9) & 4 & $67.3(26.0-108.6)$ & 5 \\
\hline \multirow[t]{4}{*}{$\mathrm{N}$} & Gabbr1 & Intact & $100.0(68.7-131.3)$ & 6 & $100.0(62.7-137.3)$ & 5 \\
\hline & & $\mathrm{Hx}$ & $137.9(111.7-164.1)$ & 6 & $93.2(61.8-124.7)$ & 6 \\
\hline & & $\mathrm{GHi}$ & $101.8(73.1-130.4)$ & 5 & $129.7(95.2-164.1)$ & 5 \\
\hline & & GHx2 & $120.9(88.8-152.9)$ & 4 & $81.7(47.2-116.2)$ & 5 \\
\hline \multirow[t]{4}{*}{$\mathrm{N}$} & Gria1 & Intact & $100.0(78.0-122.0)$ & 6 & $100.0(78.9-121.1)$ & 5 \\
\hline & & $\mathrm{Hx}$ & $96.4(76.4-116.5)$ & 6 & $67.4(42.0-92.7)^{\ddagger}$ & 6 \\
\hline & & $\mathrm{GHi}$ & $78.9(56.9-100.8)$ & 5 & 99.1 (71.4-126.9) & 5 \\
\hline & & $\mathrm{GH} \times 2$ & $109.4(84.9-133.9)$ & 4 & $77.6(49.8-105.4)$ & 5 \\
\hline \multirow[t]{4}{*}{$\mathrm{N}$} & Oprd1 & Intact & $100.0(70.3-129.7)$ & 6 & $100.0(71.3-128.7)$ & 5 \\
\hline & & $\mathrm{Hx}$ & $112.3(86.0-138.5)$ & 6 & $84.4(35.8-133.0)$ & 6 \\
\hline & & $\mathrm{GHi}$ & 77.6 (48.9-106.3) & 5 & 126.9 (73.7-180.1) & 5 \\
\hline & & $\mathrm{GH} \times 2$ & 116.5 (84.4-148.6) & 4 & $67.2(14.0-120.4)$ & 5 \\
\hline \multirow[t]{4}{*}{ G } & Cnp & Intact & $100.0(72.1-127.9)$ & 6 & $100.0(74.4-125.6)$ & 5 \\
\hline & & $\mathrm{Hx}$ & $96.0(76.2-115.8)$ & 6 & $82.0(57.6-106.5)$ & 6 \\
\hline & & $\mathrm{GHi}$ & $92.4(70.7-114.1)$ & 5 & $95.4(68.6-122.1)$ & 5 \\
\hline & & $\mathrm{GH} \times 2$ & $116.7(92.4-141.0)$ & 4 & $69.1(42.3-95.8)$ & 5 \\
\hline \multirow[t]{4}{*}{ G } & Gja1 & Intact & $100.0(75.5-124.5)$ & 6 & $100.0(77.2-122.8)$ & 5 \\
\hline & & $\mathrm{Hx}$ & $116.0(95.8-136.2)$ & 6 & $71.1(51.9-90.4)$ & 6 \\
\hline & & $\mathrm{GHi}$ & $96.4(74.3-118.5)$ & 5 & $81.3(60.2-102.4)$ & 5 \\
\hline & & $\mathrm{GH} \times 2$ & $109.6(84.9-134.4)$ & 4 & $92.9(71.8-114.0)$ & 5 \\
\hline G & Gfap & Intact & $100.0(73.6-126.4)$ & 6 & $100.0(65.3-134.7)$ & 5 \\
\hline & & $\mathrm{Hx}$ & $111.1(88.1-134.2)$ & 6 & $110.4(74.3-146.6)$ & 6 \\
\hline & & $\mathrm{GHi}$ & $91.8(66.5-117.0)^{\dagger \dagger}$ & 5 & 158.9 (119.3-198.5) & 5 \\
\hline & & $\mathrm{GH} \times 2$ & $147.5(119.2-175.7)$ & 4 & $106.6(67.0-146.2)$ & 5 \\
\hline G & Alas1 & Intact & $100.0(77.0-123.0)$ & 6 & $100.0(62.0-138.0)$ & 4 \\
\hline & & $\mathrm{Hx}$ & $95.2(77.7-112.7)$ & 6 & $107.8(71.1-144.4)$ & 6 \\
\hline & & $\mathrm{GHi}$ & $73.0(53.9-92.2) *$ & 5 & 133.5 (93.4-173.7) & 5 \\
\hline & & $\mathrm{GH} \times 2$ & 103.3 (81.9-124.7) & 4 & $87.1(46.9-127.2)$ & 5 \\
\hline G & Hif1a & Intact & $100.0(76.4-123.6)$ & 5 & $100.0(55.0-145.0)$ & 4 \\
\hline & & $\mathrm{Hx}$ & $97.2(77.4-117.0)$ & 6 & $134.7(98.4-171.0)$ & 6 \\
\hline & & $\mathrm{GHi}$ & $75.5(53.8-97.2)$ & 5 & $163.1(123.3-202.8)^{\dagger}$ & 5 \\
\hline & & $\mathrm{GH} \times 2$ & $105.1(80.8-129.3)$ & 4 & $93.2(53.5-133.0)$ & 5 \\
\hline
\end{tabular}

Each group value is set in accordance with the intact group's value set to 100 for each transcript

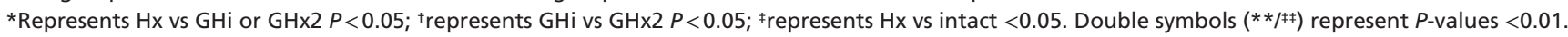

http://joe.endocrinology-journals.org DOI: $10.1530 / \mathrm{JOE}-16-0656$
๑) 2017 Society for Endocrinology Printed in Great Britain
Published by Bioscientifica Ltd. 


\section{General effects in the hippocampus}

To further study the general effect of mode of administration and category of transcript, a MMA statistical analysis was used. For the specific categories of transcripts, the MMA revealed a significant difference in the neuron- and glia-related group between GHi and GHx2 groups, with a higher expression for GHx2 (Fig. 1A). In the neuron-Hbb category, there were significant differences between both $\mathrm{Hx}$ vs GHi and Hx vs GHx2 (Fig. 1A). Furthermore, the MMA did not reveal any significant differences in the GH-related transcripts (Fig. 1A).
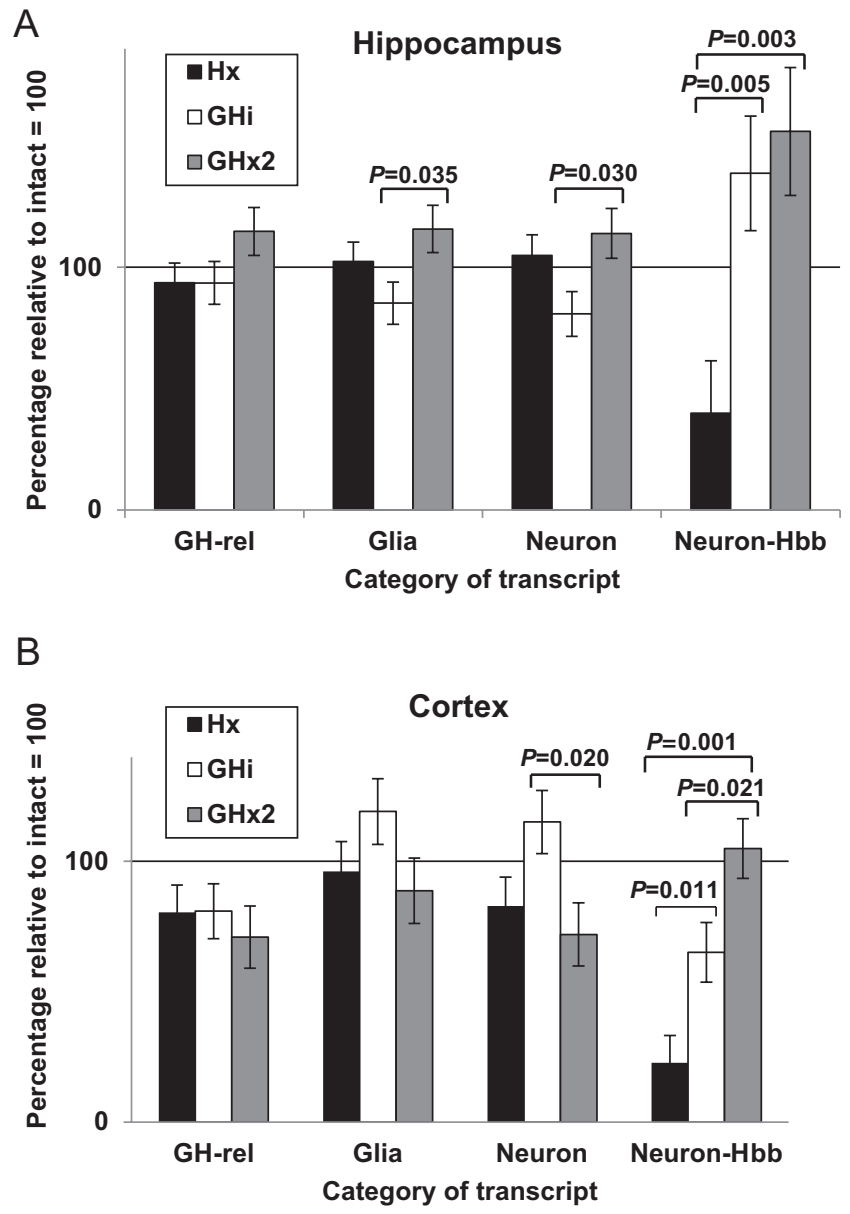

Figure 1

Levels of categories of transcripts in hippocampus (A) and cortex (B), as analysed by Q-RT-PCR. Significance levels and variation are given by mixed model analysis (MMA), see methods. All transcript levels are normalised to the level of the Gapdh transcript, the levels are therefore arbitrary but quantitative within each figure. For easier comparison, the average levels for intact rats have been set to $100 \%$. Data are presented as means $\pm 95 \%$ confidence intervals (Cls). $P$-values are given when below 0.05 .

\section{General effects in the cortex}

Specifically, there was a significant difference between GHi and GHx2 (Fig. 1B) in the neuron-related category, with negative effects of $\mathrm{GH} \times 2$ as compared to the positive effects of GHi. This finding was in contrast to the results found in hippocampal expression where the effect of GHx2 was in general larger than the effect of GHi. In the neuronHbb category, there were significant differences between $\mathrm{Hx}$ and both of GHi and GHx2 and between GHi vs GHx2 (Fig. 1B), with a higher expression for GHx2, consistent with the results in the hippocampus. The GH-related and glia-related transcripts were not significantly affected by the mode of GH-administration (NS, Fig. 1B).

\section{Possible functional associations indicated by correlation patterns}

Statistical correlation can be used to indicate which transcripts have a functional association. Thus, a statistical association between a transcript and weight increase may indicate one type of effect of GH, possibly by peripheral or direct effects of GH. In contrast, the other associations to components of the GH-IGF1 system may indicate a regulation by local components. Accordingly, it is of note that the expression of $\mathrm{Hbb}$ and Alas2 was highly associated with weight gain in both brain regions (Table 5), whereas they were neutral or negatively associated with Igf1r. For all other transcripts, there was a neutral or negative association with weight gain, except for Gja1 in the hippocampus (showed a positive association with weight gain). Further, these transcripts all showed a robust positive association with $I g f 1 r$. This was most evident in the hippocampus.

\section{Discussion}

This study aimed to investigate responses to different modes of GH administration to hypophysectomised female rats with respect to previously known GH-induced plasticity-related transcripts in the hippocampus and the cortex. The study shows that GH affects the selected transcripts differently in the hippocampus compared with the cortex albeit to a moderate degree. One exception was the neuron-Hbb category, where GHi and to larger degree GHx2 increased expression by 2-3 fold in both brain regions (Fig. 1 and Table 4). For the other transcripts, primary statistical analysis for each of the transcripts revealed only a few instances of significant differences

Published by Bioscientifica Ltd 
Table 5 Correlation matrix for weight gain, and the GH-related transcripts vs all transcripts.

\begin{tabular}{|c|c|c|c|c|c|}
\hline \multirow[b]{2}{*}{ Cat. } & \multirow{2}{*}{$\frac{\text { Transcript }}{\text { Correlations }}$} & \multicolumn{2}{|c|}{ Hippocampus } & \multicolumn{2}{|c|}{ Cortex } \\
\hline & & Weight $(\Delta)$ & Igf1r & Weight $(\Delta)$ & Igf1r \\
\hline \multirow[t]{3}{*}{ N/A } & weight $(\Delta)$ & & & & \\
\hline & $r$ & 1 & -0.009 & 1 & 0.112 \\
\hline & $P$ & & 0.969 & & 0.630 \\
\hline \multirow[t]{3}{*}{$\mathrm{GH}$} & Ghr & & & & \\
\hline & $r$ & 0.124 & 0.734 ** & 0.046 & $0.538 *$ \\
\hline & $P$ & 0.602 & $<0.001$ & 0.842 & 0.012 \\
\hline \multirow[t]{3}{*}{$\mathrm{GH}$} & Igf1 & & & & \\
\hline & $r$ & 0.205 & $0.464 *$ & $-0.461^{*}$ & 0.306 \\
\hline & $P$ & 0.386 & 0.039 & 0.035 & 0.177 \\
\hline \multirow[t]{3}{*}{$\mathrm{GH}$} & $\operatorname{lgf1r}$ & & & & \\
\hline & $r$ & -0.009 & 1 & 0.112 & 1 \\
\hline & $P$ & 0.969 & & 0.630 & \\
\hline \multirow[t]{3}{*}{$\mathrm{GH}$} & Esr1 & & & & \\
\hline & $r$ & -0.165 & 0.726 ** & 0.312 & 0.741 * * \\
\hline & $P$ & 0.476 & $<0.001$ & 0.207 & $<0.001$ \\
\hline \multirow[t]{3}{*}{$\mathrm{N}-\mathrm{Hbb}$} & $H b b$ & & & & \\
\hline & $r$ & $0.540 *$ & $-0.468 *$ & $0.627 * *$ & 0.146 \\
\hline & $P$ & 0.014 & 0.037 & 0.002 & 0.526 \\
\hline \multirow[t]{3}{*}{$\mathrm{N}-\mathrm{Hbb}$} & Alas2 & & & & \\
\hline & $r$ & $0.599 * *$ & -0.141 & $0.569 * *$ & -0.162 \\
\hline & $P$ & 0.005 & 0.553 & 0.009 & 0.495 \\
\hline \multirow[t]{3}{*}{$\mathrm{N}$} & Grin2a & & & & \\
\hline & $r$ & 0.105 & $0.843 * *$ & 0.104 & 0.771 * * \\
\hline & $P$ & 0.659 & $<0.001$ & 0.653 & $<0.001$ \\
\hline \multirow[t]{3}{*}{$\mathrm{N}$} & $D \lg 4$ & & & & \\
\hline & $r$ & -0.012 & 0.881 ** & -0.318 & 0.359 \\
\hline & $P$ & 0.958 & $<0.001$ & 0.159 & 0.110 \\
\hline \multirow[t]{3}{*}{$\mathrm{N}$} & Gabbr1 & & & & \\
\hline & $r$ & $-0.449 *$ & 0.688 ** & -0.127 & 0.758 ** \\
\hline & $P$ & 0.041 & 0.001 & 0.582 & $<0.001$ \\
\hline \multirow[t]{3}{*}{$\mathrm{N}$} & Gria1 & & & & \\
\hline & $r$ & 0.052 & 0.796 ** & 0.293 & 0.790 ** \\
\hline & $P$ & 0.823 & $<0.001$ & 0.197 & $<0.001$ \\
\hline \multirow[t]{3}{*}{$\mathrm{N}$} & Oprd1 & & & & \\
\hline & $r$ & -0.105 & $0.775 * *$ & -0.036 & $0.789 * *$ \\
\hline & $P$ & 0.651 & $<0.001$ & 0.877 & $<0.001$ \\
\hline \multirow[t]{3}{*}{ G } & Cnp & & & & \\
\hline & $r$ & 0.054 & $0.534 *$ & -0.037 & 0.427 \\
\hline & $P$ & 0.815 & 0.015 & 0.873 & 0.054 \\
\hline \multirow[t]{3}{*}{ G } & Gja1 & & & & \\
\hline & $r$ & -0.331 & 0.676 ** & $0.442 *$ & $0.521 *$ \\
\hline & $P$ & 0.143 & 0.001 & 0.045 & 0.015 \\
\hline \multirow[t]{3}{*}{ G } & Gfap & & & & \\
\hline & $r$ & 0.061 & $0.637 * *$ & -0.112 & 0.365 \\
\hline & $P$ & 0.791 & 0.003 & 0.628 & 0.104 \\
\hline \multirow[t]{3}{*}{ G } & Alas1 & & & & \\
\hline & $r$ & -0.007 & $0.712 * *$ & -0.207 & 0.233 \\
\hline & $P$ & 0.975 & $<0.001$ & 0.381 & 0.322 \\
\hline G & Hif1a & & & & \\
\hline & $r$ & -0.025 & $0.605 * *$ & -0.284 & $0.581 * *$ \\
\hline & $P$ & 0.918 & 0.005 & 0.225 & 0.007 \\
\hline
\end{tabular}

The two-tailed correlation matrix was calculated according to Pearson (see 'Materials and methods' section). The correlation coefficients $(r)$ represent analysis of all animals $(n=21)$, with significance levels $(P)$. Significant correlations are shown in bold. Category of transcript is abbreviated 'Cat.', and the specific abbreviations of each category of transcript ( $\mathrm{N}, \mathrm{N}-\mathrm{Hbb}, \mathrm{N}$ and $\mathrm{G}$ ) is found in Tables 1 and 2. N/A, not applicable. ${ }^{*} P<0.05, * * P<0.01$. between GHi and GHx2 (Table 4). Still, the MMA confirmed that the relatively moderate responses are mostly in the same direction with respect to $\mathrm{Hx}$ and intact rats across the transcripts. With regard to category of transcript, MMA revealed many cases of significant differences between GHi and GHx2. Importantly, GHi and GHx2 acted differently in the hippocampus and in the cortex. Correlation analysis between weight gain, GH-related transcripts which are local components of the GH-IGF1 system, and the specific transcripts revealed two types of associations. Overall, $\mathrm{Hbb}$ and Alas2 were associated with weight gain whereas most other transcripts were associated with the local Igflr expression. These findings are discussed below.

\section{Differences between GHi and GHx2}

There were moderate but conceptual differences in the response to the two different administration paradigms. Peripherally, this was reflected in an expected higher weight gain of GHx2 as compared to GHi (Table 3). The responses in the hippocampus and in the cortex are sequentially discussed below.

The hippocampus showed a significant difference in response between GHi and GHx2. Specifically, GHi suppressed glia- and neuron-related transcript abundance, whereas GHx2 restored abundance to intact levels (Fig. 1A). Thus, GHx2 administration could be more optimal in eliciting a response in the hippocampus regarding neuron- and glia-related transcripts, which is in agreements with reports on systemic responses to different modes of GH administration. For example, an administration frequency of 2-4 injections per day of GH optimises body growth in male Hx rats (Jansson et al. 1982). In agreement, the study by Isgaard (Isgaard et al. 1988) demonstrated that pulsatile treatment induces local Igf1 in skeletal muscle and rib growth plate more effectively than continuous $\mathrm{GH}$ in male $\mathrm{Hx}$ rats. Our results would thus indicate that $\mathrm{GHx} 2$ is more effective to elicit responses not only in the male, but also in the female hippocampus.

In contrast, in the cortex, GHi increased neuronrelated transcripts, whereas GHx2 had no effect (Fig. 1B). The glia- and GH-related categories were unaffected by administration of either GHi or GHx2 (Fig. 1). This discrepancy between the pattern of response to GHi and GHx2 in the hippocampus and in the cortex could partly be explained by generally tighter associations between the Igf $1 r$ and the other transcripts in the cortex as compared to the hippocampus (Table 5).

Published by Bioscientifica Ltd. 
Effects of $\mathrm{GH}$ administration with respect to neuron-Hbb neuroprotection and oxygenation-promoting properties

We have previously demonstrated that GH administration in female (Walser et al. 2011) and male (Walser et al. 2014) hypophysectomised rats robustly regulates the level of the $\mathrm{Hbb}$ transcript in the brain. In the present experiments, we also show that the transcript for the rate-controlling enzyme of haeme biosynthesis Alas2 is similarly affected by GH. This gives support to that GH may be linked to neuroprotection against hypoxia.

There may be several explanations to this finding. To begin with, Hx may lower the basal metabolic rate and subsequent administration of $\mathrm{GH}$ may restore the basal metabolism accompanied by an increased oxygen consumption (Goodman \& Grichting 1983). Indeed, an upregulation of brain $\mathrm{Hbb}$ has been shown after ischaemia-induced hypoxia (He et al. 2009). Furthermore, as the neuron-Hbb category responds to Hx by a considerable decrease in the levels of transcripts, in both sexes and in both brain regions, we conclude that this is likely driven by a mechanism unrelated to the effect on the other transcripts, whose generally tighter correlations to the $I g f 1 r$, instead suggests that the effects of GH may be more closely mediated to IGF-I signalling via the Igf1r (Table 5).

Taken together, it appears that endogenous neuronal (non-erythrocyte) haemoglobin in neurons is involved in neuroprotection although its function is still not fully clear.

Differences between the sexes Interestingly, when comparing the results from our previous investigations in male rats (Walser et al. 2014) with the results in the present study of female rats, there is a marked difference in response between the sexes. In both sexes, in the hippocampus, the transcripts were generally increased by GHx 2 whereas this effect was small or absent after GHi. However, in the cortex, these transcripts were unresponsive to $\mathrm{GH} 2$ but responded in opposite directions to $\mathrm{GHi}$; in females with an increase and in males with a decrease (Fig. 1A and B) (Walser et al. 2014). This indicates that the two brain regions are divergently receptive to the two different administration strategies. Other reasons put forward for sex differences in expression are that oestradiol treatment increases local GH expression in the cerebellum and in the hippocampus with only a marginal effect in the hypothalamus, and that the sex chromosome regulates GH expression within the hypothalamus (Quinnies et al. 2015). Indeed, this suggests that the two brain regions, the hippocampus and the cortex may be differentially affected by the two administration paradigms of GH in the sexes. Future studies on GH administration should preferably also include a group of sex-hormone substituted rats, in addition to the cortisol and thyroxine-substituted Hx rats.

\section{Clinical relevance}

By administration of GH in two different modes, followed by attaining the expression of sixteen transcripts we tried to provide a more comprehensive picture of the effects of GH in the hippocampus and in the cortex. Although, the mode of administration did not have a decisive importance in our female rats, $\mathrm{GHx} 2$ in spite of being more male-like than GHi, elicited a somewhat greater effect on all transcripts in the hippocampus and in particular on $\mathrm{Hbb}$ and Alas2.

Neuronal-Hbb may have neuroprotective properties, as discussed above for hypoxic neuroprotection (He et al. 2009), but, in addition, there are also indications that $\mathrm{Hbb}$ is involved in multiple sclerosis (Brown et al. 2016) and in Parkinson's disease (Shephard et al. 2014). Furthermore, a link between Hbb/Alas2 and dopamine signalling malfunction in the restless legs syndrome has been shown (Jellen et al. 2013). The fact that GHx2 decreased expression of most transcripts except $\mathrm{Hbb}$ and Alas2 in the cortex, suggests that GHi may be favourable to induce these plasticity-related transcripts in this brain region. However, such a conclusion would need confirmation in a study that also includes substitution of sex hormones.

Neuroprotective effects are most often considered to involve the acute phase of an injury, while the ensuing recovery phase involves more of effects on long-acting plasticity. Although the significant differences between modes of GH administration in the neuron- and gliacategories of transcripts were small, they may nevertheless be important for long-term plasticity after brain injuries. Specifically, chronic central treatment of a unilateral stroke with GH in adult rats was associated with slightly more rapid recovery of motor functions and with better spatial memory (Pathipati et al. 2009). Moreover, the consequences of TBI can be improved in humans by an acute/subacute and delayed administration of $\mathrm{GH}$ several years after the TBI (Maric et al. 2010). Therefore, GH administration paradigms may have significance for both acute neuroprotection and long-term plasticity and thereby the outcomes of brain injuries. 


\section{Summary}

$\mathrm{Hbb}$ and Alas2 where considerably decreased by $\mathrm{Hx}$ and robustly restored by both administration paradigms, GHx2 more efficiently than GHi, in the hippocampus and in the cortex of the female rat, which may have consequences for neuroprotective actions of GH. Regarding the other transcripts, the effects of GH were smaller. However, using the MMA, we showed that the administration of GHx2 was more effective in increasing or restoring transcript levels in the hippocampus whereas $\mathrm{GHi}$ was more effective in the cortex. Even so, it should be stated that these moderate differences may have consequences for neuroprotection against ischaemic injuries, perhaps with different profiles in different brain regions.

\section{Supplementary data}

This is linked to the online version of the paper at $h t t p: / / d x . d o i . o r g / 10.1530 /$ JOE-16-0656.

\section{Declaration of interest}

Jan Oscarsson is employed by AstraZeneca. The other authors declare that there is no conflict of interest that could be perceived as prejudicing the impartiality of the research reported.

\section{Funding}

This study was supported by grants from the Faculty of Medicine of the University of Göteborg, grants from the Swedish Government (ALFGBG-2015), the Swedish Society of Medicine, the Göteborg Medical Society and the Novo Nordisk Foundation.

\section{References}

Åberg ND, Carlsson B, Rosengren L, Oscarsson J, Isaksson OG, Ronnback L \& Eriksson PS 2000 Growth hormone increases connexin-43 expression in the cerebral cortex and hypothalamus. Endocrinology 141 3879-3886. (doi:10.1210/en.141.10.3879)

Åberg ND, Johansson I, Åberg MA, Lind J, Johansson UE, Cooper-Kuhn CM, Kuhn HG \& Isgaard J 2009 Peripheral administration of GH induces cell proliferation in the brain of adult hypophysectomized rats. Journal of Endocrinology 201 141-150. (doi:10.1677/JOE-08-0495)

Åberg ND, Johansson UE, Åberg MA, Hellstrom NA, Lind J, Bull C, Isgaard J, Anderson MF, Oscarsson J \& Eriksson PS 2007 Peripheral infusion of insulin-like growth factor-I increases the number of newborn oligodendrocytes in the cerebral cortex of adult hypophysectomized rats. Endocrinology 148 3765-3772. (doi:10.1210/en.2006-1556)

Åberg ND, Lind J, Isgaard J \& Kuhn HG 2010 Peripheral growth hormone induces cell proliferation in the intact adult rat brain. Growth Hormone and IGF Reasearch 20 264-269. (doi:10.1016/j.ghir.2009.12.003)

Armstrong CS, Wuarin L \& Ishii DN 2000 Uptake of circulating insulinlike growth factor-I into the cerebrospinal fluid of normal and diabetic rats and normalization of IGF-II mRNA content in diabetic rat brain. Journal of Neuroscience Research 59 649-660. (doi:10.1002/ (SICI)1097-4547(20000301)59:5<649::AID-JNR8>3.0.CO;2-W)

Brown N, Alkhayer K, Clements R, Singhal N, Gregory R, Azzam S, Li S, Freeman E \& McDonough J 2016 Neuronal hemoglobin expression and its relevance to multiple sclerosis neuropathology. Journal of Molecular Neuroscience 59 1-17. (doi:10.1007/s12031-015-0711-6)

D’Ercole AJ, Ye P, Calikoglu AS \& Gutierrez-Ospina G 1996 The role of the insulin-like growth factors in the central nervous system. Molecular Neurobiology 13 227-255. (doi:10.1007/BF02740625)

De Geyter D, De Smedt A, Stoop W, De Keyser J \& Kooijman R 2016 Central IGF-I receptors in the brain are instrumental to neuroprotection by systemically injected IGF-I in a rat model for ischemic stroke. CNS Neuroscience and Therapeutics 22 611-616. (doi:10.1111/cns.12550)

Devesa J, Lois N, Arce V, Diaz MJ, Lima L \& Tresguerres JAF 1991 The role of sexual steroids in the modulation of growth-hormone (Gh) secretion in humans. Journal of Steroid Biochemistry and Molecular Biology 40 165-173. (doi:10.1016/0960-0760(91)90179-9)

Eden S 1979 Age- and sex-related differences in episodic growth hormone secretion in the rat. Endocrinology 105 555-560. (doi:10.1210/endo105-2-555)

Folli F, Ghidella S, Bonfanti L, Kahn CR \& Merighi A 1996 The early intracellular signaling pathway for the insulin/insulin-like growth factor receptor family in the mammalian central nervous system. Molecular Neurobiology 13 155-183. (doi:10.1007/BF02740639)

Goodman HM \& Grichting G 1983 Growth hormone and lipolysis: a reevaluation. Endocrinology 113 1697-1702. (doi:10.1210/endo-1135-1697)

Gustafson K, Hagberg H, Bengtsson BA, Brantsing C \& Isgaard J 1999 Possible protective role of growth hormone in hypoxia-ischemia in neonatal rats. Pediatric Research 45 318-323. (doi:10.1203/00006450199903000-00005)

Hallberg M \& Nyberg F 2012 Growth hormone receptors in the brain and their potential as therapeutic targets in central nervous system disorders. Open Endocrinology Journal 6 (Supplement 1: M5) 27-33. (doi:10.2174/1874216501206010027)

He Y, Hua Y, Liu W, Hu H, Keep RF \& Xi G 2009 Effects of cerebral ischemia on neuronal hemoglobin. Journal of Cerebral Blood Flow and Metabolism 29 596-605. (doi:10.1038/jcbfm.2008.145)

Isgaard J, Carlsson L, Isaksson OG \& Jansson JO 1988 Pulsatile intravenous growth hormone $(\mathrm{GH})$ infusion to hypophysectomized rats increases insulin-like growth factor I messenger ribonucleic acid in skeletal tissues more effectively than continuous GH infusion. Endocrinology 123 2605-2610. (doi:10.1210/endo-123-6-2605)

Jansson JO \& Frohman LA 1987 Inhibitory effect of the ovaries on neonatal androgen imprinting of growth hormone secretion in female rats. Endocrinology 121 1417-1423. (doi:10.1210/endo-121-41417)

Jansson JO, Albertsson-Wikland K, Eden S, Thorngren KG \& Isaksson O 1982 Circumstantial evidence for a role of the secretory pattern of growth hormone in control of body growth. Acta Endocrinologica 99 24-30. (doi:10.1530/acta.0.0990024)

Jansson JO, Eden S \& Isaksson O 1985 Sexual dimorphism in the control of growth hormone secretion. Endocrine Reviews 6 128-150. (doi:10.1210/edrv-6-2-128)

Jellen LC, Lu L, Wang X, Unger EL, Earley CJ, Allen RP, Williams RW \& Jones BC 2013 Iron deficiency alters expression of dopamine-related genes in the ventral midbrain in mice. Neuroscience 252 13-23. (doi:10.1016/j.neuroscience.2013.07.058)

Le Greves M, Steensland P, Le Greves P \& Nyberg F 2002 Growth hormone induces age-dependent alteration in the expression of hippocampal growth hormone receptor and N-methyl-D-aspartate receptor subunits gene transcripts in male rats. PNAS 99 7119-7123. (doi:10.1073/pnas.092135399)

Le Greves M, Zhou Q, Berg M, Le Greves P, Fholenhag K, Meyerson B \& Nyberg F 2006 Growth hormone replacement in hypophysectomized http://joe.endocrinology-journals.org

DOI: 10.1530/JOE-16-0656
(C) 2017 Society for Endocrinology Printed in Great Britain 
rats affects spatial performance and hippocampal levels of NMDA receptor subunit and PSD-95 gene transcript levels. Experimental Brain Research 173 267-273. (doi:10.1007/s00221-006-0438-2)

Lobie PE, Garcia-Aragon J, Lincoln DT, Barnard R, Wilcox JN \& Waters MJ 1993 Localization and ontogeny of growth hormone receptor gene expression in the central nervous system. Brain Research Developmental Brain Research 74 225-233. (doi:10.1016/0165-3806(93)90008-X)

Lopez-Fernandez J, Sanchez-Franco F, Velasco B, Tolon RM, Pazos F \& Cacicedo L 1996 Growth hormone induces somatostatin and insulinlike growth factor I gene expression in the cerebral hemispheres of aging rats. Endocrinology 137 4384-4391. (doi:10.1210/en.137.10.4384)

MacLeod JN, Pampori NA \& Shapiro BH 1991 Sex differences in the ultradian pattern of plasma growth hormone concentrations in mice. Journal of Endocrinology 131 395-399. (doi:10.1677/joe.0.1310395)

Maric NP, Doknic M, Pavlovic D, Pekic S, Stojanovic M, Jasovic-Gasic M \& Popovic V 2010 Psychiatric and neuropsychological changes in growth hormone-deficient patients after traumatic brain injury in response to growth hormone therapy. Journal of Endocrinological Investigation 33 770-775. (doi:10.1007/BF03350340)

Martin LJ, Blackstone CD, Levey AI, Huganir RL \& Price DL 1993 AMPA glutamate receptor subunits are differentially distributed in rat brain. Neuroscience 53 327-358. (doi:10.1016/0306-4522(93)90199-P)

Mathews LS, Norstedt G \& Palmiter RD 1986 Regulation of insulinlike growth factor I gene expression by growth hormone. PNAS $\mathbf{8 3}$ 9343-9347. (doi:10.1073/pnas.83.24.9343)

McEwen BS, Gray JD \& Nasca C 201560 years of neuroendocrinology: redefining neuroendocrinology: stress, sex and cognitive and emotional regulation. Journal of Endocrinology 226 T67-T83. (doi:10.1530/JOE-15-0121)

McGauley GA 1989 Quality of life assessment before and after growth hormone treatment in adults with growth hormone deficiency. Acta Paediatrica Scandinavica Supplement 356 70-72; discussion 73-74. (doi:10.1111/j.1651-2227.1989.tb11249.x)

Nishijima T, Piriz J, Duflot S, Fernandez AM, Gaitan G, Gomez-Pinedo U, Verdugo JMG, Leroy F, Soya H, Nuñez A, et al. 2010 Neuronal activity drives localized blood-brain-barrier transport of serum insulin-like growth factor-I into the CNS. Neuron 67 834-846. (doi:10.1016/j. neuron.2010.08.007)

Nyberg F \& Hallberg M 2013 Growth hormone and cognitive function. Nature Reviews Endocrinology 9 357-365. (doi:10.1038/nrendo.2013.78)

Oscarsson J, Ottosson M, Vikman-Adolfsson K, Frick F, Enerback S, Lithell H \& Eden S 1999 GH but not IGF-I or insulin increases lipoprotein lipase activity in muscle tissues of hypophysectomised rats. Journal of Endocrinology 160 247-255. (doi:10.1677/joe.0.1600247)

Pan W, Yu Y, Cain CM, Nyberg F, Couraud PO \& Kastin AJ 2005 Permeation of growth hormone across the blood-brain barrier. Endocrinology 146 4898-4904. (doi:10.1210/en.2005-0587)

Pathipati P, Surus A, Williams CE \& Scheepens A 2009 Delayed and chronic treatment with growth hormone after endothelin-induced stroke in the adult rat. Behavioural Brain Research 204 93-101. (doi:10.1016/j.bbr.2009.05.023)

Pekny M, Leveen P, Pekna M, Eliasson C, Berthold CH, Westermark B \& Betsholtz C 1995 Mice lacking glial fibrillary acidic protein display astrocytes devoid of intermediate filaments but develop and reproduce normally. EMBO Journal 14 1590-1598.

Persson AI, Åberg ND, Oscarsson J, Isaksson OG, Ronnback L, Frick F, Sonesson C \& Eriksson PS 2003 Expression of delta opioid receptor mRNA and protein in the rat cerebral cortex and cerebellum is decreased by growth hormone. Journal of Neuroscience Research $\mathbf{7 1}$ 496-503. (doi:10.1002/jnr.10515)

Pons S \& Torres-Aleman I 1993 Estradiol modulates insulin-like growth factor I receptors and binding proteins in neurons from the hypothalamus. Journal of Neuroendocrinology 5 267-271. (doi:10.1111/j.1365-2826.1993.tb00482.x)

Quinnies KM, Bonthuis PJ, Harris EP, Shetty SRJ \& Rissman EF 2015 Neural growth hormone: regional regulation by estradiol and/or sex chromosome complement in male and female mice. Biology of Sex Differences 6 8. (doi:10.1186/s13293-015-0026-x)

Sadlon TJ, Dell'Oso T, Surinya KH \& May BK 1999 Regulation of erythroid 5-aminolevulinate synthase expression during erythropoiesis. International Journal of Biochemistry and Cell Biology 31 1153-1167. (doi:10.1016/S1357-2725(99)00073-4)

Schneider-Rivas S, Rivas-Arancibia S, Vazquez-Pereyra F, VazquezSandoval R \& Borgonio-Perez G 1995 Modulation of long-term memory and extinction responses induced by growth hormone $(\mathrm{GH})$ and growth hormone releasing hormone (GHRH) in rats. Life Science 56 PL433-PL441. (doi:10.1016/0024-3205(95)00171-2)

Shephard F, Greville-Heygate O, Marsh O, Anderson S \& Chakrabarti L 2014 A mitochondrial location for haemoglobins-dynamic distribution in ageing and Parkinson's disease. Mitochondrion 14 64-72. (doi:10.1016/j.mito.2013.12.001)

Thunell S 2006 (Far) Outside the box: genomic approach to acute porphyria. Physiological Research 55 (Supplement 2) S43-S66.

Walser M, Hansen A, Svensson PA, Jernas M, Oscarsson J, Isgaard J \& Åberg ND 2011 Peripheral administration of bovine GH regulates the expression of cerebrocortical beta-globin, GABAB receptor 1, and the Lissencephaly-1 protein (LIS-1) in adult hypophysectomized rats. Growth Hormone and IGF Research 21 16-24. (doi:10.1016/j. ghir.2010.11.002)

Walser M, Schioler L, Oscarsson J, Åberg MA, Svensson J, Åberg ND \& Isgaard J 2014 Different modes of GH administration influence gene expression in the male rat brain. Journal of Endocrinology 222 181-190. (doi:10.1530/JOE-14-0223)

$\mathrm{Xu}$ J, Li C, Yin XH \& Zhang GY 2008 Additive neuroprotection of GABA $A$ and GABA B receptor agonists in cerebral ischemic injury via PI-3K/ Akt pathway inhibiting the ASK1-JNK cascade. Neuropharmacology 54 1029-1040. (doi:10.1016/j.neuropharm.2008.01.014)

Yan H, Mitschelen M, Bixler GV, Brucklacher RM, Farley JA, Han S, Freeman WM \& Sonntag WE 2011 Circulating insulin-like growth factor (IGF)-1 regulates hippocampal IGF-1 levels and brain gene expression during adolescence. Journal of Endocrinology 211 27-37. (doi:10.1530/JOE-11-0200)

Ziello JE, Jovin IS \& Huang Y 2007 Hypoxia-Inducible Factor (HIF)-1 regulatory pathway and its potential for therapeutic intervention in malignancy and ischemia. Yale Journal of Biology and Medicine $\mathbf{8 0}$ 51-60.

Received in final form 24 February 2017

Accepted 8 March 2017

Accepted Preprint published online 8 March 2017 http://joe.endocrinology-journals.org

DOI: 10.1530/JOE-16-0656
() 2017 Society for Endocrinology Printed in Great Britain
Published by Bioscientifica Ltd 